\title{
The vitality of economic strength for social equity- an empirical study
}

\author{
Pardeep Bhasker \\ orcid.org/0000-0001-9811-8872 \\ Cochin, Kerala, India.
}

\begin{abstract}
:
The social justice is conditional on the provision of basic necessities of like at the bottom level of the social pyramid. The paper evaluates the verification and linkages between the economic strength and the social justice. The evidences have been created and validated that suggested that there are linkages and direct symmetries between the economic strength and the social justice.
\end{abstract}

KEYWORDS: Economic Strength, Social Justice, Social Security, Inclusive Development, Human Empowerment.

\section{DISCUSSION:}

\section{Social Equity}

Social equity is equity as far as the dispersion of riches, opportunities, and benefits inside of a general public. Traditionally, "equity" (particularly remedial equity or distributive equity) guaranteed that people both satisfied their societal parts and got what was their due from society.

Social equity allots rights and obligations in the organizations of society, which empowers individuals to get the fundamental advantages and weights of participation. The significant organizations can incorporate instruction, human services, government disability, work rights, and additionally a more extensive arrangement of open administrations, dynamic tariff and regulation of business sectors, to guarantee reasonable dissemination of riches, equivalent open door, equity of result, and no gross social foul play.

While the idea of social equity can be followed through Ancient and Renaissance reasoning, for example, Socrates, Thomas Aquinas, Spinoza and Thomas Paine, the expression "social equity" got to be utilized unequivocally from the 1840s. A Jesuit minister named Luigi Taparelli is normally credited with begetting the term, and it spread amid the insurgencies of 1848 with the work of Antonio Rosmini-Serbati. In the late mechanical upset, dynamic American legitimate researchers started to utilize the term all the more, especially Louis Brandeis and Roscoe Pound. From the mid twentieth century it was likewise implanted in global law and establishments, beginning with the Treaty of Versailles 1919. The prelude to set up the International Labor Organization reviewed that widespread and enduring peace can be built up just on the off chance that it is based upon social equity. In the later twentieth century, social equity was made key to the social's logic contract, 
principally by John Rawls in A Theory of Justice (1971). In 1993, the Vienna Declaration and Program of Action regard social equity as a motivation behind the human rights instruction.

The genuine inquiry confronting created industrialist nations now is the thing that sort of free enterprise to have, and what kind of riches dissemination. Among the most astute masterminds on these inquiries, few are strict egalitarians, thus even here Wehner and Brooks have drawn in a strawman. One may think current incongruities in riches are low, not on the grounds that material balance is the objective, but rather in light of the fact that human thriving is, and an excess of individuals do not have the essential material products for that prospering. Pay and riches fairness isn't the worry, however having adequate merchandise to address one's issues and satisfy one's employment is. In like manner, one may stress over the different political force that accompanies gross material disparities.

Individuals' charge over assets is generally comprehended as far as salary and riches. Salary portrays the stream of assets - what comes in. Riches is a stock - the assets that a man holds. In spite of the fact that imbalances in riches are much more prominent than disparities of wage, a great part of the writing focuses on salary as a superior marker of welfare, or if nothing else one that is less demanding to gauge.

Chart demonstrating UK conveyance of salary. Salary in many social orders has a "lognormal" shape, where individuals are clustered close to the dissemination's base however there is a long tail of wealthier individuals. Disparities in wage are frequently appeared by the Gini Coefficient, which mirrors the offer of aggregate salary going to distinctive segments of the populace. Norway has a Gini of 0.25 , France 0.31 , the USA of 0.4 and Mexico of 0.48 . A few concentrates likewise allude to the offer of individuals in the most minimal fifth (or 'quintile') with individuals in the most astounding fifth. In the UK the quintile proportion is 7.2; in some South American nations it is more than 20.

Imbalances of pay have essential ramifications for welfare. Wherever there is rivalry for products, for example, access to land or lodging, individuals on lower salaries can't pay as much as their rivals and are prone to be prohibited or minimized. The European Union distinguishes the danger of destitution with 'financial separation' from the middle or mid-point wage, where individuals' earnings are significantly not exactly different wages common of that society.

\section{Nexus between economic strength and social equity}

Monetary development with social equity requests tremendous open interest in commercial enterprises, agribusiness and social administrations. The venture of trusts on such a huge scale is conceivable just if all areas of the group hone unbending severity and stay away from all types of pomp.

In India, obvious utilization is without a doubt on the increment. All over the place extravagance structures are shooting up and the rich are straightforwardly spending phenomenal sums on relational unions and on articles of solace and extravagance, in this manner making an inauspicious complexity between substantial scale horrifying bone-dry stunning destitution and glaring wealth.

The capital assets of the nation, which could have been utilized to modernize the economy, are secured up gold and adornments or are driven underground as dark cash. Exchange union pioneers in this nation are cognizant a greater amount of the privileges of sorted out work, than of its obligations. The hour's need is higher generation and more prominent efficiency in fields and production lines. 
A nation which tries to higher expectations for everyday life can't bear the cost of lock-outs, strikes, go-moderate strategies and different types of modern strife. Advancement with social equity must be a helpful exertion on a monstrous scale, in which the cases to quick advantages must be subordinated to those of brighter children.

Social equity is an expression with distinctive essences in diverse coun-tries and among distinctive financial experts and sociologists.

In creating coun-tries under a vote based structure, social equity implies, above everything else, distributive equity or a comprehensively populist financial request. What constitutes just or unjustifiable social framework is, in a definitive examination, an issue of good judgment to be replied as indicated by one's qualities and inclinations. Be that as it may, for a democrat who puts stock in the poise of man and the hallowedness of human identity, certain conclusions are inescapable. He can't question the suggestion that each tyke, regardless of to which class he has a place, is qualified for those conditions which can help him to add to his fullest possibilities and accomplish selfimprovement and self-acknowledgment.

Concen-tration of monetary riches is politically undesirable and ethically weak on the grounds that tremendous fortunes are by and large construct not with respect to individual exertion, but rather spring from an in a general sense uncalled for and old-fashioned social framework, in which conception and heredity focus a singular's status and belonging. Un-earned livelihoods must be dynamically cleaned up and utilized for the benefit of everyone. There is no stable good or monetary avocation for them.

In a popularity based State, medieval practices had no spot. The administration has sanctioned the Monopolies and Restrictive Trade Practices Act to forestall convergence of monetary energy to the regular burden. Its new modern permitting strategy looks to check the development of imposing business model, energize crisp endeavor and give each sort of help to the little maker and the coagent part. It likewise looks to end territorial lopsided characteristics and help in reverse ranges progress mechanically.

Monetary equity, which touches the distinct individual and in addition the social request, envelops the ethical standards which direct us in planning our financial organizations. These organizations decide how every individual gains a living, goes into contracts, trades products and administrations with others and generally creates an autonomous material establishment for his or her financial sustenance. A definitive motivation behind financial equity is to free every individual to draw in innovatively in the boundless work past financial aspects, that of the brain and the soul.

Globalization is significantly more than a financial marvel. It is on the double a financial, social, social, political and lawful marvel. In financial aspects, globalization alludes to the development of speculations and ventures past national limits through, for instance, expanded universal exchange. In social terms, globalization depicts an expanded level of interconnectedness among the general population of the world and their lives, work and families. As a social marvel, it implies the trading of thoughts and qualities among societies and infers, for about, a pattern toward the improvement of a solitary world society. Political globalization alludes to the movement of political exercises from an exclusively national level to a worldwide level through intergovernmental associations, for example, the United Nations and the World Trade Organization. As a legitimate wonder, globalization is, partially, a movement in the routes in which worldwide law is made and authorized. Monetary, social, social, political and legitimate globalization were impelled by innovative advances in interchanges and the accessibility of data. Level headed discussions proceed as to the negative and beneficial outcomes of globalization in these different connections. 
One constructive outcome of the extension of business exercises on an overall scale is expanded financial development, particularly for well off nations. (For additional on this, perceive How Globalization Affects Developed Countries.) The overall population tends to concentrate on the possibly negative impacts of a worldwide economy for less affluent countries. Organized commerce is most unsafe for little organizations that can't successfully contend on the worldwide level. The abuse and manhandle of regular assets are other destructive results of expanded requests for a nation's products.

Socially, a constructive effect of globalization is the thought's widening of social equity from a national to a universal scale to incorporate the fairness, human rights and pride surprisingly of the world. The advanced partition, between those with PC and Internet access and those without, is refered to by numerous as a negative social impact of globalization that has brought about the centralization of data, and in this way control, in the hands of a little tip top.

Some consider the spread of popular society from nation to nation to be an advantage of social globalization in that the trading of thoughts, workmanship, dialect and music encourages understanding among the diverse societies of the world. On the drawback, American popular society has spread to different nations more than the way of life of whatever other country, so the alleged social trade has been to a great extent uneven.

Numerous case that a potential political advantage of globalization is that it lessens the shots of war by encouraging collaboration among countries and making nations less unfriendly toward each other. Others refer to a dangerous atmospheric devation and environmental change, because of nursery gasses transmitted by extending modern establishments, as negative political impacts of globalization.

\section{CONCLUSION:}

Social equity requires solid and intelligible arrangements in a huge number of territories. Financial, fiscal and other monetary approaches, and additionally social arrangements, consolidate particular destinations however should all be equipped towards the general social objective of advancing the welfare of a nation's subjects and progressively, in this period of worldwide association, the world's natives. The prosperity of natives requires expansive based and reasonable financial development, monetary equity, the procurement of job opportunities, and all the more for the most part the presence of conditions for the ideal advancement of individuals as people and social creatures. Macroeconomic approaches may be introduced in all their multifaceted nature by specialists or legitimized by government officials with selfserving contentions, however they can basically be separated into two gatherings: those favoring a couple and those offering an opportunity to the numerous. The same is valid for exchange strategies. The challenges experienced in explaining and actualizing such strategies in a manner that adjusts distinctive intrigues and guarantees progress towards social equity are huge, particularly for nations still during the time spent setting up their monetary, institutional and political establishments. What is basic in this setting is the conviction that the objective merits seeking after and that common endeavors are vital.

\section{REFERENCES:}

Adelman, I., \& Morris, C. T. (1973). Economic growth and social equity in developing countries. Stanford University Press.

Agyeman, J. (2003). Just sustainabilities: development in an unequal world. MIT Press.

Arbour, L. (2007). Economic and social justice for societies in transition. NYUJ Int'I L. \& Pol., 40, 1. 
Ginwright, S., \& Cammarota, J. (2002). New terrain in youth development: The promise of a social justice approach. Social Justice, 82-95.

Kuttner, R. (1987). The economic illusion: False choices between prosperity and social justice. University of Pennsylvania Press.

Marsden, K. (1969). Towards a Synthesis of economic Growth and social Justice. Int'I Lab. Rev., 100, 389.

Nussbaum, M. (2003). Capabilities as fundamental entitlements: Sen and social justice. Feminist economics, 9(2-3), 33-59.

Sen, A. K. (2000). Social justice and distribution of income. HANDBOOKS IN ECONOMICS, 16, 59-86.

Smith, J. (1997). Transnational social movements. Blackwell Publishing Ltd.

Tikly, L., \& Barrett, A. M. (2011). Social justice, capabilities and the quality of education in low income countries. International Journal of Educational Development, 31(1), 3-14. 